patients, was used to determine methotrexate (MTX) intolerance prevalence in RA patients. The MISS consisted of four domains: abdominal pain, nausea, vomiting, and behavioral symptoms, occurring before (anticipatory), after, and when thinking of MTX (associative). MTX intolerance was defined as six or more points on the MISS. Our statistical analysis was based on a descriptive study and logistic regression with SPSS20.

Results: We included 102 RA patients with a mean age of $51.60 \pm 14.33$ years, Women were predominant $(93.1 \%)$. The mean disease duration was $14.86 \pm$ 9.78 years, with a mean methotrexate use duration of $7.42 \pm 6.44$ years. The mean dose of methotrexate was $12.13 \pm 9.06 \mathrm{mg}$ per week. The prevalence of methotrexate intolerance was $55.9 \%$, and seventy-six patients $(74.5 \%)$ experienced at least one gastrointestinal symptom during MTX treatment. After MTX administration, the most prevalent gastrointestinal symptom was nausea $(93 \%$ of the intolerant patient), whereas abdominal pain occurred in $73.7 \%$ and vomiting in $57.9 \%$. These symptoms were also prevalent before and when thinking of MTX. Anticipatory nausea was reported in $45.6 \%$ and associative nausea in $54.5 \%$ of the cases, abdominal pain occurred anticipatory in $22.8 \%$ and associative in $42.1 \%$, anticipatory vomiting was the least prevalent, affecting $8.8 \%$. Behavioral symptoms affected $87.7 \%$ of intolerant patients, with restlessness being the most prominent symptom in $71.9 \%$ of them. Among the intolerant patients, 45 patients (79\%) took parenteral MTX, and $12(21.1 \%)$ took methotrexate orally. In comparison, young patients $(49.11 \pm 14.95$ years) were more intolerant to MTX than old $(54.76 \pm 13$ years, $p=0.048)$ ones. However, in univariate logistic regression analysis, we did not find any significant association between methotrexate administration route, dose, duration, and digestive intolerance.

Conclusion: Methotrexate intolerance was highly prevalent in our RA population. These results strengthen the idea that early detection of MTX intolerance may avoid effective treatment discontinuation, especially in younger patients.

REFERENCES:

[1] Bulatović M, Heijstek MW, Verkaaik M, van Dijkhuizen EH, Armbrust W, Hoppenreijs EP et al. High prevalence of methotrexate intolerance in juvenile idiopathic arthritis: development and validation of a methotrexate intolerance severity score. Arthritis Rheum. 2011 Jul; 63(7):2007-13.

Disclosure of Interests: None declared

DOI: 10.1136/annrheumdis-2021-eular.3315

\section{AB0275 RHEUMATOID ARTHRITIS AFTER CONVENTIONAL OR BIOLOGICAL THERAPY - IT REAL ROLE IN DIFFERENT LINES OF TREATMENT}

W. Rivero ${ }^{1}$, L. Ibata ${ }^{2}$, S. Martinez ${ }^{2}$, A. Rojas-Villarraga ${ }^{3}$, P. Santos-Moreno ${ }^{4}$ ${ }^{1}$ Biomab - Center for Rheumatoid Arthritis, Bogota, Colombia, Pharmaceutical chemist, Bogota, Colombia; ${ }^{2}$ Epithink Health Consulting, Epidemiology, Bogota, Colombia; ${ }^{3}$ Fundacion Universitaria de Ciencias de la Salud - FUCS, Research Division, Bogota, Colombia; ${ }^{4}$ Biomab - Center for Rheumatoid Arthritis, Bogota, Colombia, Rheumatology, Bogota, Colombia

Background: rheumatoid arthritis (RA) is a chronic and disabling autoimmune disease, with a high clinical and economic burden. This implies the need to investigate therapies that maximize clinical results. Tofacitinib is recommended as a different alternative to biologic therapy when a patient remains with moderate or high disease activity after conventional DMARDs use, or as an option after failure to biologic therapy.

Objectives: to evaluate the effectiveness of Tofacitinib in RA as first-line (after conventional DMARDs failure) or second-line treatment (after biologic therapy failure) in a real-life cohort of RA patients and its differences.

Methods: this is a descriptive retrospective cohort study conducted at a specialized center for RA in Bogota, Colombia; databases from 2017 to 2019 were used to select and study patients with indication of Tofacitinib, regardless of their previous treatment or disease status. The indication and initiation of Tofacitinib (5 mg BID or $11 \mathrm{mg}$ once daily) was an independent medical decision made as part of the individualized management of every patient. Effectiveness was evaluated in those patients who met the high adherence criteria (at least three visits with a rheumatologist per year), with no change or addition of other conventional DMARDs. Frequencies and proportions in baseline characteristics, differences in disease activity were calculated between the first and second line tofacitinib treatment. Comparisons of continuous variables data between the two patient groups were made using the t-test; the chi-square test and Fisher's exact test were used for statistical analysis of categorical variables. Logistic regressions were performed to analyze related factors with therapeutic response outcomes. Results: we included 152 RA patients who received tofacitinib: first-line (T1) ( $n=$ $85,55.9 \%)$ or second-line (T2) ( $n=67,44.1 \%)$. T1 first-line group was younger than the T2 second-line patients $(53 \pm 12.8$ years and $59 \pm 11.4$ years, p-value 0.01$)$ and they had a shorter disease duration than T2 patients (11.8 vs. 12.8 years, $\mathrm{p}$-value 0.01$)$. Comparative analysis of response to treatment showed a reduction in DAS28 at 3, 6 and 12 months in both study groups. The response in disease activity at 3 months was a major factor related to 6-month response (OR 13.4,
95\% Cl 4.5-39.4, p value 0.000), while non-response at 3 months were associated with no response at 6 months of follow-up. Baseline DAS28 was significantly associated with response at 12 months (OR 1.9, 95\% Cl 1.11-3.25, p-value 0.028). At 12 months of treatment, both groups showed disease response and control according to the DAS28 from baseline, but a higher proportion of T1 patients achieved remission ( $45 \%$ vs $23 \%$ ). A subgroup analysis to evaluate T2 second-line Tofacitinib therapy showed no statistically significant differences in any response criteria according to the number of previously received biologicals.

Table 1. Regression analysis (risk of response of the disease at 6 and 12 months of treatment with Tofacitinib)

\begin{tabular}{lcccccc}
\hline \multirow{2}{*}{ Factor } & \multicolumn{3}{c}{ Response at Month 6 } & \multicolumn{3}{c}{ Response at Month $12^{*}$} \\
\cline { 2 - 7 } & OR & IC95\% & P value & OR & IC95\% & P value \\
\hline Age & 1.00 & $0.97-1.03$ & 0.788 & 1.02 & $0.98-1.06$ & 0.211 \\
Male & 1.82 & $0.65-5.08$ & 0.251 & 0.81 & $0.27-2.38$ & 0.709 \\
Duration of RA & 0.99 & $0.94-1.04$ & 0.908 & 1.02 & $0.96-1.08$ & 0.444 \\
Positive Rheumatoid Factor & 0.81 & $026-2.56$ & 0.730 & 0.63 & $0.17-2.26$ & 0.485 \\
Positive Anti-CCP & 0.34 & $0.068-1.6$ & 0.189 & & & \\
Initial DAS28 & 1.61 & $1.04-2.49$ & 0.033 & 1.9 & $1.11-3.25$ & 0.018 \\
First line & 0.44 & $0.19-1.01$ & 0.054 & 1.47 & $0.56-3.83$ & 0.423 \\
Treatment period & 1.12 & $0.80-1.55$ & 0.492 & 1.1 & $0.75-1.61$ & 0.607 \\
Dose: 11 mg. & 0.95 & $0.42-2.13$ & 0.904 & 0.75 & $0.258-1.9$ & 0.565 \\
Response at Month 3 & 13.42 & $4.57-39.4$ & 0.000 & 2.32 & $0.87-6.18$ & 0.091 \\
\hline
\end{tabular}

${ }^{*}$ Positive Anti-CCP at month 12 was omitted because of collinearity

Conclusion: Tofacitinib is an effective treatment option for patients with RA after conventional DMARDs and in patients after biologic therapy failure, but maybe is better used it as a T1 first-line of treatment. Further studies are required to determine the real role of tofacitinib in different lines of RA treatment.

Disclosure of Interests: Wilberto Rivero: None declared, Linda Ibata: None declared, Susan Martinez: None declared, Adriana Rojas-Villarraga: None declared, Pedro Santos-Moreno Speakers bureau: Pedro Santos-Moreno has received fees for conferences from: Abbvie, Biopas-UCB, Bristol, Janssen, Pfizer Sanofi., Consultant of: Pedro Santos-Moreno has received fees for counseling and advisory boards from: Abbvie, Abbott, Biopas-UCB, Bristol, Janssen, Pfizer, Roche, Sanofi., Grant/research support from: Pedro Santos-Moreno has received research grants from: Abbvie, Abbott, Biopas-UCB, Bristol, Janssen, Pfizer, Roche, Sanofi. DOI: 10.1136/annrheumdis-2021-eular.3770

\section{AB0276 HOW FAST CAN METHOTREXATE BE ESCALATED IN RHEUMATOID ARTHRITIS? A MULTICENTRE, PARALLEL-GROUP RANDOMIZED CONTROLLED TRIAL (MEIRA)}

S. Jain ${ }^{1}$, V. Dhir ${ }^{1}$, A. Aggarwal ${ }^{2}$, S. Maurya ${ }^{2}$, R. Gupta ${ }^{3}$, B. Leishangthem ${ }^{1}$, A. Khullar ${ }^{1}$, V. Dhawan ${ }^{4}$, G. Naidu ${ }^{1}$, S. K. Sharma ${ }^{1}$, A. Sharma ${ }^{1}$, S. Jain ${ }^{1}$. ${ }^{1}$ PGIMER, Division of Clinical Immunology and Rheumatology, Department of Internal Medicine, Chandigarh, India; ${ }^{2}$ SGPGIMS, Department of Clinical Immunology and Rheumatology, Lucknow, India; ${ }^{3}$ AIIMS, Department of Rheumatology, New Delhi, India; ${ }^{4}$ PGIMER, Department of Experimental Medicine and Biotechnology, Chandigarh, India

Background: Literature regarding the optimal dose escalation strategy of methotrexate (MTX) in RA is scant and ambiguous (1). Concerns regarding the safety of rapid escalation may lead to delayed attainment of the optimal dose and treatment target.

Objectives: To compare the efficacy, safety and tolerability of fast versus usual dose escalation of oral MTX in RA.

Methods: This multicenter, open-label (assessor blinded) RCT included patients with active $R A$ ( $S J C \geq 2$ and $T J C \geq 4$ ) aged $18-55$ years, not on DMARDs (excep $\mathrm{HCQ}$ and/or low-dose prednisolone) and with disease duration $<5$ years. Patients were randomized 1:1 into two groups with the same starting dose of oral MTX ( $15 \mathrm{mg} /$ week), but escalated either by $5 \mathrm{mg}$ every 2 weeks (fast escalation group) or $5 \mathrm{mg}$ every 4 weeks (usual escalation group), till a maximum of $25 \mathrm{mg} / \mathrm{wk}$ Primary outcome was proportion of EULAR good responders at 16 weeks. Secondary outcomes were change in DAS28-3 and EULAR responders (good or moderate) at 8 and 16 weeks, change in Indian $\mathrm{HAQ}$ at 16 weeks, and symptomatic (questionnaire based) and laboratory adverse effects over 16 weeks. RBC MTX polyglutamate-3 levels were measured using HPLC in both groups. There was an open-label extension phase till 24 weeks (use of other DMARDs was permitted beyond 16 weeks if target was not met), and DAS28-3 at 24 weeks was compared. Trial Reg: CTRI/2018/12/016549

Results: 178 patients (mean age 39.8 (8.6) years, $84 \%$ females) with mean disease duration of 1.9 (1.4) years were randomized (89 in each group). Mean DAS28ESR-3 and DAS28CRP-3 at enrollment were 6.3 (0.9) and 5.4 (1.1). At 16 weeks, there was no significant difference in good EULAR response by DAS28ESR-3 (5.6, 7.9\%, $\mathrm{p}=0.9$ ) or DAS28CRP-3 $(28.1,22.5 \%, \mathrm{p}=0.8)$ between the two groups (Figure 1). 
The change in DAS28-ESR-3 at 8, 16 and 24 weeks (or by DASCRP-3, not shown) and improvement in HAQ at 16 weeks were also not significantly different (Table 1). Notably, there was no significant difference in symptomatic GI or CNS adverse effects, incidence of cytopenia, transaminitis or rates of drug discontinuation. RBC MTX polyglutamate-3 levels at 8 and 16 weeks were also similar (Table 1).

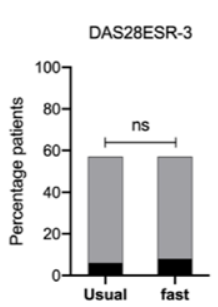

Intention-to-Treat analysis $(\mathrm{n}=178)$

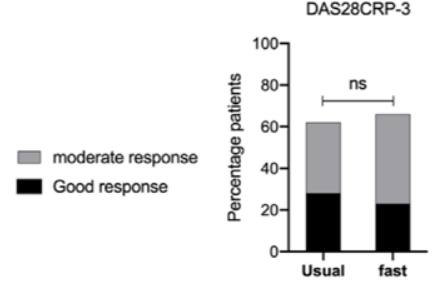

Per-protocol analysis ( $n=139)$
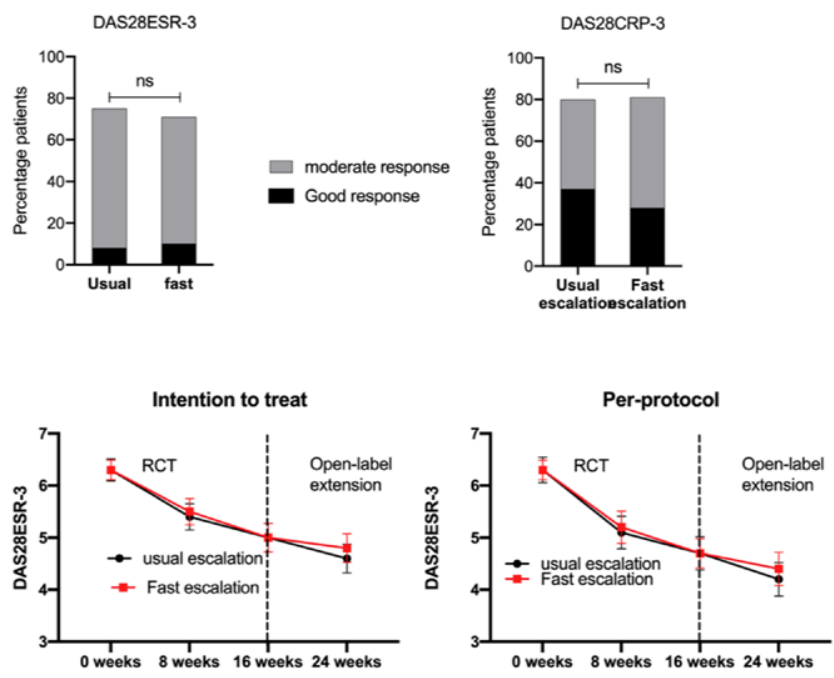

Figure 1. EULAR response and change in DAS28ESR-3 over time

Table 1. Key secondary efficacy and safety outcomes

\begin{tabular}{|c|c|c|c|}
\hline Parameter & Usual & Fast & p-value \\
\hline \multicolumn{4}{|l|}{ Efficacy } \\
\hline \multicolumn{4}{|l|}{ Delta DAS28-ESR-3 $($ Mean \pm SD) } \\
\hline \multicolumn{4}{|l|}{$-8 w k$} \\
\hline -ITT $(n=178)$ & $-0.9 \pm 1.0$ & $-0.8 \pm 0.9$ & 0.5 \\
\hline$-P P(n=139)$ & $-1.2 \pm 1.0$ & $-1.1 \pm 1.0$ & 0.5 \\
\hline \multicolumn{4}{|l|}{$-16 w k$} \\
\hline -ITT & $-1.3 \pm 1.1$ & $-1.3 \pm 1.0$ & 0.9 \\
\hline$-P P$ & $-1.6 \pm 1.1$ & $-1.6 \pm 0.9$ & 1 \\
\hline \multicolumn{4}{|l|}{-24 wk } \\
\hline -ITT & $-1.6 \pm 1.3$ & $-1.5 \pm 1.1$ & 0.3 \\
\hline$-P P$ & $-2.1 \pm 1.2$ & $-1.8 \pm 1.1$ & 0.14 \\
\hline Delta Indian HAQ (16 wk) & $-0.7 \pm 0.6$ & $-0.8 \pm 0.6$ & 0.2 \\
\hline \multicolumn{4}{|l|}{ Adverse effects } \\
\hline Serious AE & 0 & 0 & - \\
\hline Death & 0 & 0 & - \\
\hline \multicolumn{4}{|l|}{ Symptomatic $A E$ ever $n(\%)$} \\
\hline Vomiting & $7(8)$ & $7(8)$ & 1 \\
\hline Nausea & $22(26)$ & $26(30)$ & 0.5 \\
\hline Stomach ache & $16(19)$ & $17(20)$ & 0.9 \\
\hline Loss of appetite/bad taste & $21(25)$ & $27(31)$ & 0.3 \\
\hline Lethargy & $20(24)$ & $21(25)$ & 1 \\
\hline Dizziness & $19(23)$ & $16(19)$ & 0.5 \\
\hline Irritability/anxiety & $14(16)$ & $14(16)$ & 1 \\
\hline \multicolumn{4}{|l|}{ Laboratory AE ever ${ }^{*}[n / N$ times done $(\%)]$} \\
\hline Transaminitis episodes (>40IU/L) & $52 / 224(23)$ & $52 / 219(24)$ & 0.9 \\
\hline -Significant (>80 IU/L) & $5 / 224(2)$ & $8 / 219(4)$ & 0.4 \\
\hline Thrombocytopenia episodes (<150000/uL) & $10 / 224(5)$ & $13 / 218(6)$ & 0.5 \\
\hline -Significant $(<100000 / \mathrm{uL})$ & $2 / 224(1)$ & $2 / 218(1)$ & 1 \\
\hline Leucopenia episodes (<4000/uL) & $2 / 224(1)$ & $3 / 220(1.5)$ & 0.8 \\
\hline -Significant (<3500/uL) & $1 / 224(0.5)$ & $2 / 220(1)$ & 0.8 \\
\hline \multicolumn{4}{|l|}{ Methotrexate levels } \\
\hline \multicolumn{4}{|l|}{ MTX-polyglutamate-3 $(\mathrm{nmol} / \mathrm{L})$} \\
\hline$-8 w k$ & $25.8 \pm 10.5$ & $26.9 \pm 13.6$ & 0.6 \\
\hline-16 wk & $40.7 \pm 20.9$ & $40.1 \pm 23.4$ & 0.9 \\
\hline
\end{tabular}

${ }^{*}$ Ever=any time during the studyITT= intention-to-treat, $\mathrm{PP}=$ per-protocol, $\mathrm{AE}=$ adverse effect
Conclusion: A faster escalation of MTX ( $5 \mathrm{mg}$ every 2 weeks) reaching $25 \mathrm{mg} /$ week by 4 weeks did not have a significantly higher rate of adverse effects (symptomatic or laboratory) compared to an escalation by $5 \mathrm{mg}$ every 4 weeks. Although not more efficacious, it may shorten the time to recognize MTX failure, and optimize treat-to-target

\section{REFERENCES:}

[1] Visser K, Katchamart W, Loza E, et al. Multinational evidence-based recommendations for the use of methotrexate in rheumatic disorders with a focus on RA: integrating systematic literature research and expert opinion of a broad international panel of rheumatologists in the $3 E$ Initiative. Ann Rheum Dis. 2009;68(7):1086-93

Disclosure of Interests: None declared

DOI: 10.1136/annrheumdis-2021-eular.3864

\section{AB0277 ASSOCIATION BETWEEN INTRA-ERYTHROCYTE METHOTREXATE POLYGLUTAMATE CONCENTRATION AND CLINICAL RESPONSE IN RHEUMATOID ARTHRITIS IN PATIENTS TREATED WITH METHOTREXATE INJECTABLE SUBCUTANEOUSLY}

M. Poudret ${ }^{1}$, M. Norman ${ }^{2}$, S. Hodin ${ }^{3}$, A. S. Amouzougan ${ }^{1}$, K. Boussoualim¹, A. Coassy ${ }^{1}$, T. Neel ${ }^{1}$, T. Thomas ${ }^{1,2}$, X. Delavenne ${ }^{3}$, H. Marotte ${ }^{1,2} .{ }^{1} \mathrm{CHU}$ SaintEtienne, Rheumatology, Saint-Etienne, France; ${ }^{2}$ Université de Lyon, SAINBIOSE LBTO, INSERM 1059, Saint-Etienne, France: ${ }^{3}$ Université de Lyon, SAINBIOSE DVH, INSERM 1059, Saint-Etienne, France

Background: Methotrexate (MTX) is the first-line treatment for rheumatoid arthritis (RA). Due to its short half-life, blood MTX dosage is not performed in current practice. Erythrocyte MTX-polyglutamate (MTX-PG), which penetrates into the red blood cells, would be correlated with the area under the MTX curve and would be more accessible for dosing. When treatment is initiated, its concentration correlates with efficacy and therapeutic adherence.

Objectives: To determine the interest of erythrocyte MTX-PG dosage in case of failure of $1^{\text {st }}$ line MTX treatment.

Methods: In this single-centre cross-sectional study, RA patients presenting for consultation at the Saint-Etienne University Hospital, with a stable dose of MTX for more than 3 months at least $15 \mathrm{mg} /$ week subcutaneously with either clinical remis sion (DAS28 $<2.6$ ) or active disease (DAS28>3.2) were included between July $2^{\text {nd }}$ 2018 and May $28^{\text {th }} 2020$. In order to assess therapeutic compliance, the patient completed the compliance questionnaire of Rheumatology (CQR) questionnaire. The determination of erythrocytic MTX-PG was performed on a $5 \mathrm{~mL}$ blood sample by liquid chromatography method for the determination of the different PG forms. Results: Sixty patients were included, 34 in the active RA group and 26 in the RA group in remission. One patient withdrew his consent. Only $16 \%$ of patients were observed with a CQR score $>80 \%$. Patients in remission were leaner with a longer duration of disease and MTX treatment. The sex ratio, RA status, creatinine clearance and MTX dose was not different in both groups. The CQR was better in the remission group than in the active RA group. However, total MTX-PG was not different in the two groups. The same results were observed for the different forms of MTX-PG 1, 2, 3 or 4. In contrast, in the remission PR group, total MTX-PG or MTX-PG2, 3, 4 and 5 correlated inversely with $\mathrm{BMI}$ while MTX-PG3 correlated positively with $\mathrm{BMI}$ in the active PR group. In the active PR group, MTX-PG5 correlated with MTX dose.

Conclusion: MTX-PG dosage is not a biomarker of good response to MTX in our study. However, compliance is a key factor to be considered in RA with active disease in adapting patient management.

\section{REFERENCES:}

[1] Pasma A, Boer E den, Spijker A van 't, Timman R, Bemt B van den, Busschbach JJV, et al. Nonadherence to disease modifying antirheumatic drugs in the first year after diagnosis: comparing three adherence measures in early arthritis patients. Rheumatology 2016;55:1812-1819.

[2] Haandel L van, Becker ML, Leeder JS, Williams TD, Stobaugh JF. A novel high-performance liquid chromatography/mass spectrometry method for improved selective and sensitive measurement of methotrexate polyglutamation status in human red blood cells. Rapid Commun Mass Spectrom RCM 2009;23:3693-3702.

[3] Dervieux T. Pharmacogenetic and metabolite measurements are associated with clinical status in patients with rheumatoid arthritis treated with methotrexate: results of a multicentred cross sectional observational study. Ann Rheum Dis 2005;64:1180-1185.

Disclosure of Interests: Marion POUDRET: None declared, Myriam Norman: None declared, Sophie Hodin: None declared, Adamah Stanislas AMOUZOUGAN: None declared, Karima BOUSSOUALIM: None declared, Astrid Coassy: None declared, Tiphany Neel: None declared, THIERRY THOMAS: None declared, Xavier DELAVENNE: None declared, Hubert MAROTTE Speakers bureau: Pfizer, Nordic, Paid instructor for: Amgen, Consultant of: Novartis, Grant/ research support from: Nordic DOI: 10.1136/annrheumdis-2021-eular.4028 